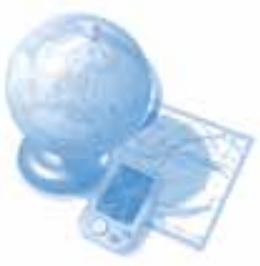

Brian Bowe

Physics Education

Research Group

Dublin Institute of

Technology

Kevin St

Dublin 8

Ireland

brian.bowe@dit.ie

\section{Implementing Physic s Education Research to Inform and Enhance Pedagogical Approaches}

\begin{abstract}
Since 1999 the School of Physics in the Dublin Institute of Technology has been critically analysing its pedagogical strategies, leading to a reconsideration of teaching, learning and assessment practices. In 2001, the Physics Education Research Group was established to develop, implement and evaluate pedagogical initiatives in physics education and to undertake rigorous education research studies to inform and evaluate these developments. Various innovative pedagogical approaches including problembased learning, project-based learning, peer instruction and eLearning have been implemented. These pedagogical developments were informed by education research studies which examined student learning, lecturers' conceptions of learning and teaching and group interactions and dynamics. Further education research studies are continually carried out to evaluate all pedagogical approaches in order to enhance and continually improve the students' learning experience. These studies, which include both qualitative and quantitative methods, are conducted primarily using phenomenography, action research or evaluative research approaches.
\end{abstract}

\section{Introduction}

Over the last fifteen years significant changes in student profile, stemming primarily from mass education and dramatic changes in information technology, have led to the scrutiny of the suitability and appropriateness of teaching practices in higher education ${ }^{1}$. The effects of the changes in student profile have arguably been most acutely felt in physical sciences education due to the dramatic decrease in the number of students choosing to pursue science in undergraduate studies (IOP Report, 2001 ${ }^{2}$; Task Force Report, $2002^{3}$ ). In 1999, in the context of Irish higher education, the drop in student applicants meant that new entrants to physics programmes tended to have less physics knowledge and were not as motivated as students in previous years, which in turn led to poor attendances in lectures and high dropout rates. This put pressure on physics educators to not only recruit students but also to motivate and support the students in order to improve retention rates.

Since 1999 the School of Physics in the Dublin Institute of Technology (DIT) has been critically analysing its pedagogical strategy, leading to a reconsideration of teaching and assessment practices that has manifested itself in a push towards student-centred learning and an acknowledgement of the importance of lifelong learning skills. This move, which has been informed by education research, with its emphasis on theory and practice, and physics education research, with its emphasis on the how students learn physics and develop conceptual understanding ${ }^{4}$, has led to the introduction of many innovations that promote student-centred learning as physics lecturers not only take a critical look at what is being taught but also how it is being taught. This has led to awareness, among staff, of the importance and potential of student-centred and active learning, and specifically, to the development and introduction of a physics problembased learning course in 2001.

Although many of the reasons for changing to problem-based learning were primarily pedagogical, another factor was the increased importance that industry was putting on the key skills whose development is inherent in the problem-based learning process. Also, the effects of fewer students choosing to pursue physics at all levels of education had lead to a reduction in students' academic qualifications entering the physics programmes which in turn led to the problems mentioned above and caused difficulties in maintaining the academic standard. The problem-based learning course was developed to address these problems and make the subject more appealing to entrants. However, in changing the whole approach to teaching and learning, it was important to ensure the course standard and quality was maintained. The primary benefactors of this innovation had to be the students, and its success had to be measured in terms of their 
learning and learning experiences. Therefore the problembased learning staff team developed an evaluation strategy that concentrated on the students, their knowledge and their skill-based learning outcomes ${ }^{5}$. The project to develop, implement and evaluate the problem-based learning course was the first of many significant and rigorous physics education research projects undertaken within the School of Physics.

\section{Establishment of the Physics Education Research Group}

To undertake the development, implementation and evaluation of the problem-based learning course, in addition to other research projects to inform curriculum development and teaching and assessment practices, the Physics Education Research Group was set up in 2001. The main areas of research were, and still are, the development, implementation and evaluation of new and appropriate teaching and assessment strategies, studies of student learning and misconceptions, evaluation of the effectiveness of different learning resources and teaching methodologies and the development of learning resources to enhance student learning

The research undertaken by this group is heavily informed by previous education research studies for although physics education has remained relatively unchanged for over fifty years $^{6,7}$ there is an abundance of physics education research literature. Many of the studies reported in the literature have examined the effectiveness of the traditional pedagogical approaches within physics education and reported many shortcomings. These approaches tend to be teacher-centred and for the most part, the priority within a physics course is to transmit the 'correct' information to the students'. The shortcomings of these approaches, as revealed by physics education research, have become more apparent with the changes in student profile, due to such things as mass education, diversity, competition and information technology ${ }^{8}$. One possible cause may lie in the suggestion that traditional physics education tends to assume that systematically and repetitively solving simple algorithmic problems will develop an understanding of the physics concepts and principles, as well as an appreciation of the role they play in solving problems $^{8,9}$. This is evident in the way standard physics textbooks are presented (e.g. Young et $\mathrm{al}^{10}$ ). Research findings have demonstrated that problem solving by itself does not develop a deep understanding of concepts and principles, even though some students can often become proficient problem solvers by developing the ability to solve these problems through recognition of when to use an appropriate equation $^{8,11-13}$. Many studies have revealed that students, who could easily solve standard textbook problems, were often unable to relate the results to other, more complex situations $^{14}$

Another shortfall of traditional physics courses arises from the tendency to teach with the attitude that students are 'blank slates'. Students are 'given' the information and are then required to repetitively solve problems in order to develop conceptual understanding. However, results from physics education and cognitive research show that students begin a physics course with their own conceptual framework, developed either through their own experience of the world or through common sense ${ }^{7,15}$. The conclusion drawn from much of this research is that physical science educators need to provide a learning environment that encourages the construction and reconstruction of knowledge and understanding ${ }^{4}$

In summary, there appears to be an obvious contradiction in traditional physics education. Two of the principal goals of a physics programme are to develop conceptual understanding and problem-solving skills, but to achieve this students are 'given' the information and then repetitively solve quantitative problems ${ }^{7}$. However, education research has shown that the students do not develop conceptual understanding from solving these problems and furthermore they cannot develop as adept problem-solvers because they don't have the conceptual understanding. These realisations have led to a growing awareness of the need to move towards more student -centred learning approaches informed by the constructivist learning theory. Research by Angell el $\mathrm{al}^{16}$ has suggested that if physics education is to prepare physicists for 'tomorrow's society', it should be characterised by more student-centred learning approaches and a stronger emphasis on knowledge in context.

The purpose of the Physics Education Research Group was to learn from, and build on, this research to develop appropriate student-centred learning environments. It is a central goal of the group to ensure that within these learning environments the students move away from rote and surface learning to a more constructivist learning experience within which they can develop their conceptual understanding and problem-solving skills. Every aspect of each of the pedagogical approaches was informed by previous education research and physics education research, and in addition the processes of change, development, implementation and evaluation were rigorously researched as they happened, and continue to happen, by the Physics Education Research Group.

In the following sections, the research methodologies and methods used within the Physics Education Research Group are described. In the subsequent sections, three pedagogical approaches are described along with the research studies that have informed their development, implementation and enhancement.

\section{Research Methodologies and Methods}

The Physics Education Research Group uses the following research methodologies:

- Phenomenography

- Action Research

- Formative Evaluation

Phenomenography is an empirical research methodology that was designed to answer questions about thinking and learning, especially in the context of education research ${ }^{17,18}$. It is concerned with the relationships that people have with the world around them and aims to elucidate the different possible conceptions that people have for a given phenomenon. Phenomenography is sometimes seen as a subset of phenomenology ${ }^{19}$ but interestingly, phenomenography was not originally derived from the phenomenological philosophy ${ }^{20}$ nor did it emerge or derive from phenomenology ${ }^{21}$. In the phenomenographic approach the objective is to find the qualitatively different ways of experiencing or thinking about the same phenomena ${ }^{22}$. It assumes that there are a limited number of qualitatively different ways in which different people experience a certain phenomenon ${ }^{17,22}$. For instance, Bowden et $\mathrm{al}^{13}$ used this research methodology to investigate students' 
understanding of displacement, velocity and frames of reference. Sharma et al $^{23}$ also adopted a phenomenographic methodology to describe the variations in the way in which students understood the concept of gravity. The Physics Education Research Group uses this approach to examine students' conceptual understanding and problem solving abilities $^{24,25}$, as well as lecturers' conceptions of learning and teaching ${ }^{26}$. The findings from these research studies have informed the development and facilitation of the various pedagogical strategies.

The problem-based learning initiatives were designed, implemented and evaluated through a collaborative action research project ${ }^{5}$. Action research is "any systematic inquiry conducted by teacher researchers to gather information about the ways that their particular school operates, how they teach, and how well their students learn"27. All the pedagogical approaches are formatively evaluated in order to continually enhance and develop different aspects of the courses including assessment ${ }^{28}$, facilitation, resources and scaffolding.

\section{Research Methods}

Although different research methods have been used within the research studies, the dominating method has been the open and deep interview, which is carried out in a dialogical manner ${ }^{29}$ and always recorded and transcribed before being analysed. However, other methods include:

- Pre and Post Qualitative Tests (Concepts Tests)

- Pre and Post Quantitative Tests

- Questionnaires, surveys and inventories

- Observations

The pre and post concept tests have included the Force and Motion Conceptual Evaluation (FMCE) ${ }^{30}$, the Force Concept Inventory ${ }^{31}$, the Mechanics Baseline Test ${ }^{12}$, the Heat and Temperature Conceptual Evaluation (HTCE) ${ }^{32}$ and the Thermal Concept Evaluation (TCE) 3 $^{33}$. As many of these inventories were developed within the context of the American education systems it was first necessary to validate them within the context of the Irish education system and make adjustments where appropriate. The validation process involved administering the inventory to a small number of students followed by interviews in which the level of their conceptual understanding was ascertained. In certain instances, customised concepts tests were developed to ensure suitability in a given context. Pre and post quantitative tests were also developed which included questions that ranged from 'end-of-chapter' type questions to open contextrich questions. Other tests were developed that were both quantitative and qualitative in nature but examined a specific area of physics or set of skills. For instance a test was developed to examine the development of laboratory knowledge and skills.

Other inventories are used to examine students' attitudes to physics, expectations, approaches to learning and learning styles, and lecturers' approaches to teaching (Approaches to Teaching Inventory) ${ }^{34}$. As with the concepts tests, when using inventories that were developed in a different context it is necessary to ensure that they are valid with the context of the research. It should also be noted that these inventories are used as one research method within a myriad of research methods in a triangulation process.

Questionnaires and surveys are also used to obtain the students perceptions, feelings and opinions relating to particular aspects of the pedagogical approaches, such as the assessment strategy, the learning activities and resources and the facilitation.

Observations, which are recorded, are used to study group dynamics, and norms, and the learning process within the group environment. Through rigorous discourse analysis of the group interactions and outcomes, it is possible to study and analyse the ways students learn, create meaning and reconceptualise their knowledge. The purpose of all these research methods is to obtain data which when analysed will inform the teaching and learning practices within the School.

\section{Pedagogical Approaches}

Although new pedagogical approaches have been introduced within the School of Physics, many of the modules are still taught through the more traditional education methods of didactic lectures, standard tutorials and practical-driven laboratories. Many of the research projects examine the benefits and shortcomings of these learning activities with the purpose of making enhancements and informing the change to the new pedagogical approaches. While eLearning is used extensively throughout many modules it will not be discussed here as both the traditional and new pedagogical approaches are now supported, to different degrees, online. An on-line learning resource centre was developed, which includes online tutorials, assignments, of quizzes, individual students' feedback pages, calendar, noticeboard and details of the laboratory programme. In the problem-based learning course, the feedback from both the formative and summative assessments is provided through the online $\operatorname{sit}^{28}$. The students are also required to complete regular online multiplechoice quizzes as part of the overall continuous assessment.

In the following sections the traditional education approach and three of the new pedagogical approaches that have been 
introduced are described along with the research that has informed their development, implementation and enhancement.

\section{'Traditional' Education}

The Physics Education Research Group has conducted a number of research studies that have examined the effectiveness of different elements of the traditional education approach. In particular, one study investigated the development of students' conceptual knowledge in core areas of physics and their problem-solving abilities ${ }^{24,25,35}$. The research methods used were the pre and post concepts tests and the open deep interviews. One of the findings from the study demonstrated that students entering third level education have little or no conceptual mechanics knowledge, regardless of whether they had studied physics in second level (within the Irish education system). The study, which involved approximately 600 students from two different higher education institutes, also revealed that the vast majority of students' conceptual understanding remains relatively unchanged after formal instruction in mechanics at higher level. The study also showed that the majority of students do not approach problem solving in a strategic or scientific manner. Most of the students use a 'plugand-chug' approach by identifying variables and trying to find some formula, appropriate or not. Many of the findings from this study provide the rationale for the change to more student-centred approaches such as problem-based learning and peer-instruction. It also provides a benchmark against which to measure the success of these new pedagogical approaches.

\section{Another ongoing research study is examining the} effectiveness of traditional laboratory practices with the purpose of identifying deficiencies which can be addressed through the introduction of improved structures, resources, experiments and laboratory assessments. The study examines students' competences in different aspects of the laboratory, such as tabulating data, drawing and analysing graphs and calculating uncertainties. This study, which is ongoing, is also informing the move towards more project-based laboratory practices.

Another ongoing research project is examining the traditional students' perceptions of physics and approaches to learning. The purpose of this project is to compare the effects of different pedagogical approaches on the students' views' of physics and on how they learn.

\section{Problem-based Learning}

Problem-based learning is now used as the sole pedagogical approach in physics within the first year of four degree programmes (Physics Technology, Science with Nanotechnology, Physics with Medical Physics and Bioengineering, and Physical and Life Sciences). It was chosen as a pedagogical model as it was felt it could address the problems outlined previously and make the subject more appealing to entrants. The contextual, group-based and experiential learning elements of the approach instill the motivation required for the students to adopt a deep approach to their learning and encourage them to take more responsibility and independence in the learning process. In this way, this approach better supports the development of the students' conceptual understanding and problemsolving skills. The problembased learning team felt that the purpose of introducing this initiative was not only to help students develop an understanding of the conceptual nature of physics but also to support the development of the skills and competences associated with being a physicist. The problem scenarios focus on key concepts and enable students to develop problem-solving abilities and to become competent in applying their knowledge to solve problems. However, there are also traditional tutorials integrated into the process to allow for learning through cognitive apprenticeship and repetitive exercises.

An induction programme for students was developed after which the first year physics syllabus is covered by approximately 25 problems which are 'real', engaging, place the group in a 'professional' role, and require the students to make assumptions, approximations, and deal with omitted information. After a few problems the students become more aware of their roles and of the expectations the tutors have of them as individuals and as group members. The group is continuously assessed and the students are given regular feedback. A complete set of assessment criteria for the group process was developed at the outset, and includes such factors as the individual level of contribution, peer-teaching, questioning and completion of group-assigned tasks ${ }^{28}$. Collaborative assessment is introduced about halfway through the academic year after negotiation of the assessment criteria. From this point on, after each problem each student is required to self-assess their own contribution to the group process $^{28}$.

All stages of the development and implementation of the problem-based learning course have been informed by research studies carried out by the Physics Education 
Research Group. Indeed, the course itself was developed, implemented and evaluated through collaborative action research ${ }^{5,36,37}$. This research provided valuable information after one year of the course so that substantial changes could be made to the structure of the course and the assessment methods and criteria. The research methods used within this research study were student evaluations, concept tests, quantitative tests, interviews and focus groups.

The change from traditional teaching to problem-based learning met many challenges and obstacles, least of which was the reluctance of a substantial number of physics staff to get involved in, or even support, the initiative. In order to devise strategies to support the change, the Physics Education Research Group undertook a research project which set out to investigate the implications that physics lecturers' conceptions of teaching and learning may have for the use of problem-based learning in physics education ${ }^{26}$. Previous research had shown that if problem-based learning is to be successfully implemented it requires lecturers who use student-focused teaching approaches and have studentfocused conceptions of teaching and learning. This research studied the teaching approaches currently used by physics lecturers in departments where problem-based learning courses had been introduced and examined their conceptions of teaching and learning. It examined the approaches and conceptions of both the lecturers involved in these courses and the lecturers with no involvement, as well as those opposed to the use of problem-based learning. Specifically it determined the relationship between the lecturers'

focused conceptions of teaching and learning. However, this study also revealed that the majority of lecturers' conceptions of teaching and learning, and hence their teaching approaches, are affected by their teaching contexts. Many of these lecturers do not feel their current teaching contexts are appropriate to support the use of student-centred learning approaches. Therefore if the lecturers with compatible conceptions of teaching and learning introduce the new pedagogical approach, there are many other lecturers who might be persuaded to get involved, if they perceive their teaching contexts are appropriate. The research findings provided possible explanations for the shortcomings of traditional education as identified by previous education research, particularly in terms of the development of conceptual understanding and problem-solving skills. As conceptual understanding is not something that is seen as a priority and it is perceived that problem-solving skills are developed adequately with current pedagogical practices, many lecturers do not see the need to change to studentcentred learning approaches such as problem-based learning.

Similar to the study within the traditional education approach, research examined the development of students' conceptual knowledge in core areas of physics and their problem-solving abilities within the problem-based learning course ${ }^{25,35}$. Again, the research methods used were the pre and post concepts tests and the open deep interviews. Unlike the students within a traditional education environment, the problem-based learning students showed a substantial increase in their conceptual understanding after completing the course. The findings from this study also highlighted areas where improvements were necessary. For instance, when the FMCE was used to examine students' conceptual understanding in mechanics it revealed there was little gain in their understanding of Newton's third law. Figure 1 shows that pre and post test scores from the FMCE along with the percentage gains. It should be noted that the gain is expressed in terms of what Hake defines as the normalised gain, which is the average increase in students' scores divided by the average increase that would have resulted if all students had perfect scores on the post-instruction test. When the problem-based learning tutors were made aware of the findings and reviewed the set of problems they realised that Newton's third law was not explicitly dealt with.

\section{Peer Instruction}

Within programmes and modules where the introduction of problem-based learning was not feasible the Physics Education Research Group looked at other ways of facilitating a student-centred learning environment within a traditional lecturebased environment. The group felt that many of the weaknesses of the traditional

conceptions of teaching and learning and their perceptions of problem-based learning and the relationship between their perceptions of the teaching contexts and the teaching approaches they adopt. The research revealed only a minority of the physics lecturers currently have compatible studentlecturing system could be addressed by using Peering Instruction $(\mathrm{PI})^{38,39}$. This is a widely used pedagogy in which lectures are interspersed with short concept questions designed to reveal common misunderstandings and to actively engage students in lecture courses. Using the PI approach, 
the lecturer starts the lecture with a short introduction of the topic and then presents a concept question with four possible answers. The students are asked to vote individually on which answer they think is correct and their level of confidence. The students are then put into small groups and asked to convince their peers that their answer is correct (peer instruction). The students are then asked to vote again on the answer. The lecturer then explains the correct answer after which another concept question can be posed that examines the same concept. If the voting results show that there is still some confusion on the topic the lecturer can spend a bit more time on the confusing issues. The voting system can be by a show of hands, flash cards or computerised voting system (Classroom Response System). However, the show of hands and the flash cards tends to be very inefficient and harder for the tutor to facilitate. There are also problems with students not putting up their hand or card for any answer or putting it up for more than one answer. The PI approach has been widely used in the United States and has been largely championed in the area of physics by Eric Mazur $^{38,40}$. Mazur and others (Fagen et $\mathrm{al}^{40}$ ) have shown that peer instruction is applicable to large lecture groups (up to 250 students) and they have shown that the measured gain (using pre and post tests) in students' understanding is on average $40 \%$, which is far higher than students attending traditionally taught courses.

Published research ${ }^{38,40}$ has shown that PI can significantly enhance the learning experience for students. The results show that attendance improves and what is more, attention and student involvement increases. The tests show that this teaching style engenders a better understanding of the fundamental concepts and discourages a number of bad study habits such as rote memorisation and exclusive focus on problem solving. Mazur reports that the students' energy and enthusiasm during the discussions are contagious. He also claims that once one has experienced it, it is difficult to revert to lecturing to a passive and mostly silent audience.

Peer Instruction has recently been introduced into a number of modules within the School of Physics and researchers within the Physics Education Research Group are currently evaluating the process in terms of student learning and determining effective and efficient ways in which the process can be facilitated. This research project entails taking one module, Nuclear Physics, in which PI has been introduced and evaluating its success in terms of students' attendances, motivation, interaction and learning. As in the research studies mentioned previously, pre and post concepts test are used to determine the levels of learning.

\section{Project-based Laboratories}

When the problem-based learning course was initially introduced all the theory part of the course was taught through problem-based learning but the laboratory kept the traditional first year practicals, workbook and assessment criteria. Evaluation of the laboratory sessions showed that the students felt that the laboratories were inconsistent with the educational philosophy of the rest of their course. A decision was made to expand the problem-based learning philosophy into the laboratory. Experiments were designed in such a way that they became projects for which the students had to work in groups and were only given an objective and a list of equipment available in the laboratory. Each group has to write a proposal explaining how they intend to reach the objective or solve the problem. The students are assessed on their proposal, laboratory logbook, group work, and end of project report. A pilot research study was undertaken to compare the conceptual understanding of students' working in the project laboratory, to those working in a traditional physics laboratory. This preliminary study indicated that project-based physics laboratory work can improve students' understanding of physics concepts $^{41}$. It also revealed that students learning through these laboratories have a stronger awareness of their learning and the skills they develop than their traditional counterparts. A more extensive study has recently been undertaken and the data is currently being analysed in order to make enhancements to this approach.

\section{Conclusions}

In recent years one dramatic change in Higher Education that has occurred is the move towards the use of a more 'studentcentred' approach. The motivation and rationale behind this move to student-centred learning has been driven and informed by extensive education research studies that have examined how students learn and what factors determine the quality and type of learning. Student-centred learning pedagogical approaches require the active participation of the students and involve scaffolding and supports to allow students to construct their knowledge and understanding. In the School of Physics in the Dublin Institute of Technology, this move towards student-centred learning has been informed by education research and specifically physics education research. In addition the processes of development, implementation and evaluation have been extensively researched by the Physics Education Research Group. This group has conducted rigorous research studies to ensure that the new pedagogical approaches are successful by identifying shortcomings and maximising the benefits. Research has 
been carried out which looked at the process of change itself and examined student learning and development in order to inform teaching, learning and assessment practices.

\section{Acknowledgements}

The author would like to acknowledge the other members of the Physics Education Research Group, Dr. Robert Howard, Dr. Siobhan Daly, Dr. Cathal Flynn, Laura Walsh and Paul Irving. The author would also like to thank Prof. Matthew Moelter, from California State University, for his substantial contributions to the research while on sabbatical with the group during the last academic year.

\section{References}

1. Ramsden, P. (1998) Learning to Lead in Higher Education, London: Routledge.

2. Institute of Physics (IOP) Report on the Inquiry into Undergraduate Teaching, (2001) Physics: Building a Flourishing Future, London, IOP Publishing Ltd.

3. Task Force on the Physical Sciences Report (2002) Report and Recommendations, Irish Government Publications.

4. McDermott, L. C. (2004) Physics Education Research: the key to student learning, Physics World, IOP Publishing Ltd, Bristol.

5. Bowe, B. and Cowan, J. (2004) A comparative evaluation of problem-based learning in Physics: A lecture-based course and a problem-based course, in Savin-Baden, M. and Wilkie, K. (eds), Challenging Research into Problembased Learning, (London: SRHE / Open University Press).

6. Knight, R. D. (2002) An instructor's guide to introductory physics, Addison Wesley, San Francisco.

7. Redish, E. F. (2003) Teaching Physics with Physics Suite, John Wiley and Sons, Rosewood.

8. McDermott, L. C. (1991) What we teach and what is learned - closing the gap, Am. J. Phys., 59, 301-315.

9. Leonard, W. J., Dufresne, R. J. and Mestre, J. P. (1996) Using qualitative strategies to highlight the role of conceptual knowledge in solving problems, Am. J. Phys., 64(12), 1495 - 1503

10. Young, H. D., Freedman. R. A., Sandin, T. R., Lewis Ford, A. (1999) Sears and Zemansky's University Physics $\left(10^{\text {th }}\right.$ ed.), Addison Wesley Publishing Company, New York.

11. Clement, J., (1982) Students preconceptions in introductory mechanics, Am. J. Phys., 50(1), 66 - 71.

12. Hestenes D., Wells M., (1992) A Mechanics Baseline Test, The Phys. Teach., 30, 159-166.

13. Bowden, J., Dall'Alba, G., Martin, E., Laurillard, D., Marton, F., Master, G., Ramsden, P., Stephanau, A. and Walsh, E. (1992) Displacement, velocity, and Frames of reference: Phenomenographic studies of students' understanding and some implications for teaching and assessment, Am. J. Phys., 60(3), $262-269$.

14. Trowbridge D., McDermott L. (1981) Investigation of student understanding of the concept of acceleration in one dimension, Am. J. Phys., 49(3), $242-253$.

15. Halloun I. A., Hestenes D. (1985) The initial knowledge state of college physics students, Am. J. Phys., 53(11), 1043 - 1055.

16. Angell, C., Guttersrud, Ø., Henriksen, E. K., and Isnes, A. (2004) Physics: Frightful, But Fun. Pupils' and Teachers' View of Physics and Physics Teaching, Science Education, 88, 683 - 706.

17. Marton, F. (1981) Phenomenography - describing conceptions of the world around us, Instructional Science, 10, 177-200.

18. Marton, F. (1986) Phenomenography - a research approach to investigating different understandings of reality, Journal of Thought, 21, 28-49.

19. Burrell, G., and Morgan, G. (1979) Sociological paradigms and organizational analysis. Hants, England: Gower Publishing Company Limited.

20. Uljens M. (1992) Phenomenological features of phenomenography. Report No. 1993:03, Department of Education and Educational Research, University of Göteborg. 
21. Hasselgren, B. and Beach, D. (1997) Phenomenography - "a good-for-nothing brother" of phenomenology? Higher Education Research and Development, 16(2), 191-202.

22. Marton, F. (1994) Phenomenography. In T. Husen and T. N. Postlethwaite (Eds.), The international encyclopaedia of education ( $2^{\text {nd }}$ ed., Vol. 8, pp. 4424-4429). Oxford, U.K., Pergamon.

23. Sharma, M., Millar, R., Smith, A. and Sefton, I. (2004) Students' understandings of gravity in an orbiting spaceship, Research in Science Education, 34, 267-289.

24. Walsh, L., Howard, R., Harvey, J. and Bowe, B. (2005) Investigation of the Relationship between Students Conceptual Understanding and Problem Solving Skills in Optics. Education Conference at OPTO-Ireland 2005, Dublin, Ireland, April 4-6.

25. Walsh, L., Howard, R. G. \& Bowe, B., (2006), A phenomenographic study of conceptual knowledge and its relationship to problem-solving ability in physics, in Conference proceedings, Australian Institute of Physics, 17th National Congress, December 3-8.

26. Bowe, B. (2005) What are the Implications of Lecturers' Conceptions of Teaching and Learning for the Use of Problem-based Learning in Physics Education, MA Thesis, (Dublin: Dublin Institute Of Technology).

27. Mills, G. E. (2003) Action research: A guide for the teacher researcher (p4). Upper Saddle River, NJ: Merrill/ Prentice Hall.

28. Bowe, B. (2005) Assessing Problem-based Learning: A Case Study of a Physics Problem-based Learning Course in Barrett, T., MacLabhrainn, I. and Fallon, H. (eds), Handbook of Enquiry and Problem-based Learning: Irish Case Studies and International Perspectives, (Galway: CELT) pp. 103-112.

29. Booth, S. A. (1997) On Phenomenography, learning and teaching, Higher Education Research and Development, 16, 135-159.

30. Thornton, R. K. and Sokoloff, D. R. (1998) Assessing student learning of Newton's laws: The force and motion conceptual evaluation and the evaluation of active learning laboratory and lecture curricula, Am. J. Phys., 66 (4), $338-352$.

31. Hestenes D., Wells M. \& Swackhamer G. (1992), Force Concept Inventory, The Phys. Teach., 30, 141-158.

32. Thorton, R. K. and Sokoloff, D. K. (2001) Heat and Temperature conceptual Evaluation: http:// physics.dickinson.edu/ wp_web/wp_resources/ wp_assessment.html\#HTCE [2006, June 15].

33. Yeo, S. and Marjan, Z. (2001) Introductory thermal concept evaluation: assessing students' understanding. Physics Teacher, 39, 496-504.

34. Trigwell, K, Prosser, M. and Taylor, O. (1999), Relations between teachers' approaches to teaching and students' learning, Higher Education, 37, 57-70.

35. Walsh, L., Howard, R. G. and Bowe, B. (2007) Development of conceptual knowledge in mechanics - a study, Submitted to American Journal of Physics.

36. Bowe, B., Flynn, C., Howard, R., Daly, S. (2002) Teaching First Year Physics Using Problem Based Learning, UK Learning and Teaching Support Network, Problem-Based Learning in Physics Workshop, University of Leicester, Leicester, UK.
37. Bowe, B., Flynn, C., Howard, R., and Daly, S. (2005) Problem-based Learning Physics Course in the Dublin Institute of Technology,. PossiBiLities - a Practice Guide to Problem-based Learning in Physics and Astronomy. Higher Education Academy (HEA), Physics Science Centre, Hull.

38. Mazur, E. (1997) Peer Instruction - A User's Manual, Prentice Hall, New Jersey.

39. Crouch, C. H., and Mazur, E. (2001) Peer instruction: Ten Years Experience and Results, Am. J. Phys., 69, 970-977

40. Fagen A. P., Crouch, C. H., Mazur E. (2002) Peer Instruction: Results from a range of Classrooms, The Physics Teacher, 40, 206.

41. Howard, R. (2004) The Development, Implementation and Evaluation of a Project-based Laboratory, $P B L$ International Conference, Cancun, Mexico, June 13-19. 